\title{
BMJ Open Association between infection with Helicobacter pylori and platelet indices among school-aged children in central Ethiopia: a cross-sectional study
}

\author{
Kellyann Baxendell, ${ }^{1}$ Sosina Walelign, ${ }^{2}$ Mehret Tesfaye, ${ }^{2}$ Moges Wordofa, ${ }^{2}$ \\ Dessie Abera, ${ }^{2}$ Abiyot Mesfin, ${ }^{2}$ Mistire Wolde, ${ }^{2}$ Kassu Desta, ${ }^{2}$ Aster Tsegaye, ${ }^{2}$ \\ Bineyam Taye ${ }^{\circ}$
}

To cite: Baxendell K, Walelign S, Tesfaye M, et al. Association between infection with Helicobacter pylori and platelet indices among school-aged children in central Ethiopia: a cross-sectional study. BMJ Open 2019:9:e027748. doi:10.1136/ bmjopen-2018-027748

- Prepublication history and additional material for this paper are available online. To view these files, please visit the journal online (http://dx.doi. org/10.1136/bmjopen-2018027748).

Received 6 November 2018 Revised 7 March 2019 Accepted 8 March 2019

Check for updates

(C) Author(s) (or their employer(s)) 2019. Re-use permitted under CC BY-NC. No commercial re-use. See rights and permissions. Published by BMJ.

${ }^{1}$ Department of Biology, Colgate University Division of Natural Sciences and Mathematics, Hamilton, New York, USA

${ }^{2}$ Department of Medical Laboratory Sciences, College of Health Sciences, Addis Ababa University, Addis Ababa, Ethiopia

Correspondence to

Dr Bineyam Taye;

btaye@colgate.edu

\section{ABSTRACT}

Objective Previous clinical studies in adults from developed countries have implicated Helicobacter pylori infections in the development of thrombocytopenia. However, studies in children, particularly those from lowincome countries, are unusually scarce. We examined the association between $H$. pylori infection and platelet indices in young Ethiopian school children.

Design Cross-sectional study

Setting This study was conducted in five elementary schools located in central Ethiopia.

Participants Blood and stool samples were collected from 971 children across five elementary schools in Ethiopia. H. pylori infection was diagnosed using stool antigen and serum antibody tests, and haematological parameters were measured using an automated haematological analyser. An interviewer-led questionnaire administered to mothers provided information on demographic and lifestyle variables. The independent effects of $H$. pylori infection on platelet indices were determined using multivariate linear and logistic regressions.

Study outcomes $H$. pylori-infected children had a lower average platelet count and mean platelet volume than uninfected after adjusting the potential confounders (adjusted mean difference: $-20.80 \times 10^{9} / \mathrm{L} ; 95 \% \mathrm{Cl}$ -33.51 to $-8.09 \times 10^{9}, \mathrm{p}=0.001$ and adjusted mean difference: $-0.236 \mathrm{fL} ; 95 \% \mathrm{Cl}-0.408$ to $-0.065, \mathrm{p}=0.007$, respectively). Additionally, $H$. pylori-infected children had lower red blood cell counts (adjusted mean difference: $-0.118 \times 10^{12} / \mathrm{L} ; 95 \% \mathrm{Cl}-0.200$ to $-0.036, \mathrm{p}=0.005$ ) compared with non-infected.

Conclusion Our study from a developing country provides further support for an association between $H$. pylori infections and reduced platelet indices in young Ethiopian school children, after controlling for potential confounders. Further research is needed, particularly longitudinal studies, to establish causality.

\section{INTRODUCTION}

The role of Helicobacter pylori infection as a potential cause of serious upper gastrointestinal diseases has been increasingly appreciated. There is now good evidence
Strengths and limitations of this study

- Exposure to Helicobacter pylori infection was assessed using highly sensitive and specific $H$. pylori serological tests.

- Key outcomes (platelets indices) were done using a standard automated haematology

- We could not thoroughly investigate the previous use of antiplatelet agents, which is known to affect platelets indices.

- One of the current study limitations is its cross-sectional design, which makes it difficult to attribute causality on the observed association.

that infection with this organism is the principal cause of acute and chronic gastritis, atrophic gastritis, ${ }^{1-3}$ and is widely accepted as the cause of the majority of peptic ulcer diseases and associated complications of bleeding in adults. ${ }^{45}$ More recently, however, there is growing interest in investigating the effects of $H$. pylori in extragastroduodenal diseases. ${ }^{67}$ Our group's previous work in Ethiopia has found a higher prevalence of anaemia and decreased growth trajectory among $H$. pylori-infected children compared with non-infected. ${ }^{8}{ }^{9}$ This observation has led us to expand investigations into other extragastroduodenal involvement of $H$. pylori in a resource-limited setting. In particular, the effect of $H$. pylori on platelet indices has not been investigated in Ethiopia. Previous studies in various clinical settings from developed countries reported an increased platelet recovery after successful eradication of $H$. pylori infection among patients with idiopathic thrombocytopenic purpura (ITP). ${ }^{10-13}$ Additionally, meta-analysis demonstrated that patients receiving treatment had a greater increase in platelet count from baseline compared with untreated controls, regardless 
of the outcome of eradication therapy. ${ }^{14}$ However, the possibility of platelet recovery due to the eradication of bacteria other than $H$. pylori or immune-modulating effects of the treatment itself is difficult to exclude.

The mechanisms by which $H$. pylori infection can cause low platelet count are still unclear, ${ }^{12}{ }^{15}$ but plausible mechanisms have been proposed. One hypothesis that has attracted attention is that $H$. pylori may hijack the host's immune system through molecular mimicry, where molecules from the bacteria mimic host antigens and activate T lymphocytes to cause an immune response. ${ }^{12} 15$ The antibody induced by $H$. pylori then cross-reacts with platelet glycoprotein antigens and leads to excessive destruction of platelets. ${ }^{15-17}$

While the role of $H$. pylori in low platelet counts and ITP disease aetiology is intriguing, most studies to date are conducted in high-income countries on adult populations and lack data in children from low-income countries, where $H$. pylori is a very common bacterial infection, infecting more than $40 \%$ of children. ${ }^{18}{ }^{19}$ Furthermore, most of the available evidence to date comes from retrospective studies of symptomatic ITP patients in clinical settings, which is prone for selection bias and is difficult to apply in an apparently healthy population who may have been infected with $H$. pylori subclinically prior to ITP. It is, therefore, important to assess the association between $H$. pylori infection and platelet parameters in apparently healthy populations. This may provide clues for the subclinical link between $H$. pylori and platelet indices prior to ITP diagnosis. Therefore, the aim of this study was to investigate any possible association between $H$. pylori infection and platelet indices among apparently healthy primary school children in Ethiopia.

\section{STUDY SETTING AND DESIGN}

A two-part cross-sectional study was conducted in the towns Ziway and Sululta, which are both located in the Oromia region of Ethiopia, approximately $160 \mathrm{~km}$ South and $30 \mathrm{~km}$ North from the capital city, Addis Ababa, respectively. The region surrounding Sululta town has an altitude of $2450 \mathrm{~m}$ above sea level, with average temperatures ranging from $15^{\circ} \mathrm{C}$ to $18^{\circ} \mathrm{C}$, while the town of Ziway has an elevation of $1643 \mathrm{~m}$ above sea level and is adjacent to Lake Ziway (Lake Dambal). The populations of the two towns are roughly similar: Ziway's population is estimated to be 43660 and Sululta's population is estimated to be 49000 . The first part of the data collection took place in Ziway town between June and July 2016, while the second part of the study occurred in Sululta from April to June 2017. We used a single-stage cluster sampling to recruit participants from the schools. Out of the possible nine governmental primary schools in Sululta town, three (Laga dima, Wasarbi and Abdi Boru) were selected randomly. Additionally, two primary schools (Sher and Batu) were included from Ziway town. In each school, students aged 4-14 years, who were willing to provide demographic information and biological specimens, participated in this study.

\section{MEASUREMENT AND DATA COLLECTION}

We first approached the local health department in both towns and visited each school prior to the beginning of data collection to explain to school principals and teachers about the goal and nature of the study. Students were approached through their school principal and asked to bring their mothers to school. The investigators then invited mothers and their children to participate after the objective of the study was explained using a written information sheet. After the mother or legal guardian of the child signed the written consent form, an interviewer-led questionnaire was administered to collect information on selected demographic, lifestyle and behavioural factors in both towns. Information that was collected included, but was not limited to, the student's age, sex, residency, sanitary conditions, hygiene, eating habits and deworming status. Furthermore, parents' monthly income, educational status and occupation were collected to determine the student's socioeconomic status. The questionnaire was first designed in English and then translated and pretested in local languages, such as Amharic and Oromiffa languages. In addition to the questionnaire data, mothers in both towns were provided with a small leak-proof plastic container and clean wooden applicator sticks to bring a sufficient stool sample to ascertain the child's $H$. pylori and intestinal parasite infection status. Furthermore, a $5 \mathrm{~mL}$ blood sample was collected from each child using a vacutainer tube and transported to Sher Ethiopia and St. Paul's Hospital laboratories for haematological analysis.

\section{LABORATORY TESTING}

\section{H. pylori stool antigen test}

H. pylori antigen rapid test was conducted to detect active H. pylori infection (Cortez Diagnostics, California, USA). The capture antibody used for this enzyme immunoassay was a mixture of monoclonal anti- $H$. pylori antibodies and the detection antibody was a mixture of peroxidase-conjugated monoclonal anti- $H$. pylori antibodies. A small amount of stool was homogenised with a buffer solution, and two drops of the stool/buffer mixture were added to the test well. After $15 \mathrm{~min}$, the test was read. The development of two lines, the control $(\mathrm{C})$ line and the test $(\mathrm{T})$ line, indicated an $H$. pylori-positive test result, while the development of only the $\mathrm{C}$ line indicated a negative test result. In the instances where the $\mathrm{T}$ line was significantly fainter than the $\mathrm{C}$ line, the results were interpreted and recorded as positive.

\section{H. pylori antibody test}

A similar antibody rapid test was conducted to detect any past or current infections, without differentiation between the two. This rapid test was a double antigen 
chromatographic lateral flow immunoassay, where 1-2 drops of serum were added to the test well and after $15 \mathrm{~min}$, the test was read. The development of both the $\mathrm{C}$ line and the $\mathrm{T}$ line indicated a positive test result, while the development of only the $\mathrm{C}$ line was indicative of a negative test result. As it was with the stool antigen test, when the $\mathrm{T}$ line was significantly fainter than the $\mathrm{C}$ line, the results were interpreted and recorded as positive.

\section{Platelet measurements}

Two millilitres of whole blood samples was drawn from a forearm vein, collected into tubes containing EDTA between 9:00 and 10:00 and analysed within 2 hours after venipuncture using an automated haematological analyser: CELL-DYN 800 Hematology Analyzer (Abbott, Illinois, USA) and Sysmex KX-21N Hematology Analyzer (Sysmex, Kobe, Japan) at Sher Ethiopia and St. Paul's Hospitals' Haematology laboratory, respectively. The analysers aspirate the blood sample, dilute, and count platelets and measure mean platelet volume (MPV). The instruments were monitored daily with normal, high and low controls provided by the manufacturer before running the specimens to ensure the quality of haematological analyses. Additionally, the automated haematology analysers also provided leucocyte and erythrocyte counts, and measured MCV and haemoglobin, and calculated haematocrit, mean cell haemoglobin $(\mathrm{MCH})$ and MCH concentration (MCHC).

\section{Outcome and exposure variables}

The primary study outcome was platelet counts (cells/ $\mu \mathrm{L}$ ) and MPV (continuous variables). 'Exposure to $H$. pylori infection' was defined as a positive result of either H. pylori stool antigen or serum antibody tests.

\section{Statistical analysis}

Demographics and laboratory data from both towns were cleaned, coded and merged for proper analysis using IBM SPSS Statistics V.24. Mean and SD for continuous variables and proportions for categorical variables are reported. Prior to investigating, the association between H. pylori infection and platelet indices, univariate analyses were used to identify the possible confounders. Variables that were associated with both exposure and outcome variables in the crude analysis using statistical significance at $\mathrm{p}<0.3$ were considered to be possible confounders. These included sex, place of residence, age, family size, maternal education and occupation, water source, toilet type and waste disposal site. Additionally, we included variables previously shown in the literature to be associated with low platelet indices, such as intestinal parasite status. ${ }^{20}$ The primary outcomes of the current analysis were platelet count (cells $/ \mu \mathrm{L}$ ) and MPV. Our hypothesis that $H$. pylori infection would be associated with lower platelet counts (continuous variable) was assessed using generalised linear models. We first examined the crude mean difference between $H$. pylori-positive and $H$. pylo$r i$-negative individuals, and then we repeated the analysis while adjusting for the possible confounders using backwards elimination. These analyses were repeated for MPV, red blood cell (RBC) and white blood cell (WBC).

Further analyses were carried out to assess the association between $H$. pylori infection and platelet categories (polytomous outcome variable) using multinomial logistic regression. Multinomial regression is the most appropriate technique in a situation where the dependent variables are categorical and have more than two categories. In our multinomial regression analysis, platelet counts were sorted into three categories: low $\left(<150 \times 10^{9} / \mathrm{L}\right)$, high $\left(>450 \times 10^{9} / \mathrm{L}\right)$ or normal $\left(150 \times 10^{9}-450 \times 10^{9} / \mathrm{L}\right)$. Platelet counts less than $150 \times 10^{9} / \mathrm{L}$ or greater than $450 \times 10^{9} / \mathrm{L}$ were used for classification of thrombocytopenia or thrombocytosis, respectively. We also categorised MPV level as low $(<7 \mathrm{fL})$, high $(>10.5 \mathrm{fL})$ or normal $(7-10.5 \mathrm{fL})$, respectively. The cut-offs for both the platelet count classifications and the MPV classifications were set as described by the British Journal of Haematology. ${ }^{21}$ Covariates were kept in the model if they changed the coefficient of exposure (H. pylori infection) by $>10 \%$ or if they were independently associated with the outcome at $\mathrm{p}<0.10$. Probability values $<0.05$ were considered statistically significant for main effects. A similar pattern of demographic and lifestyle distributions was observed among study subjects who had complete outcome data and all respondents using sensitivity analysis (data not shown).

\section{Patient and public involvement}

Patients and the public were not involved in the development of the research question, the design of the study, the recruitment and the conduct of the research. They were informed regarding the research goals and parameters to be measured before starting the study.

\section{RESULTS}

\section{Selected demographic characteristics and $\boldsymbol{H}$. pylori infection} status

A total of 1038 school children were invited to participate in the study, of which $971(93.5 \%)$ and $955(92.0 \%)$ provided demographic information and biological specimens, respectively. Of these, $55.5 \%$ (539/971) were female and a slight majority $56.4 \%$ (546/971) were living in a rural area. The age range of the study participants was 4-14 years (mean age, 9.95). Most mothers 57.9\% (565/971) reported using indoor-pipe water as their primary drinking source, and $82.3 \%(802 / 971)$ used a traditional pit toilet. Maternal demographic characteristics showed that $56.4 \%(550 / 971)$ of the mothers did not have a formal education, and $32.0 \%(311 / 971)$ were housewives. The prevalence of $H$. pylori infection was $35.9 \%(343 / 954)$ (table 1$)$.

\section{Univariate analysis for relationships between potential confounders and $\boldsymbol{H}$. pylori infection}

The crude association between demographic variables and infection with $H$. pylori was analysed using univariate logistic regression. Sex, place of residence, age, maternal education and occupation, water source, family size, toilet 
Table 1 Sociodemographic characteristics and Helicobacter pylori infection status of school children in Ziway and Sululta towns, Ethiopia, 2016-2017 ( $n=971)$

\begin{tabular}{|c|c|c|}
\hline Variables & No & $\%$ \\
\hline \multicolumn{3}{|l|}{ Sex } \\
\hline Male & 432 & 44.5 \\
\hline Female & 539 & 55.5 \\
\hline \multicolumn{3}{|c|}{ Place of residence } \\
\hline Urban & 546 & 56.4 \\
\hline Rural & 422 & 43.6 \\
\hline \multicolumn{3}{|l|}{ Age (years) } \\
\hline$\leq 5$ & 91 & 9.4 \\
\hline $6-10$ & 425 & 43.9 \\
\hline $11-14$ & 453 & 46.7 \\
\hline \multicolumn{3}{|c|}{ Maternal education } \\
\hline Informal only & 550 & 56.4 \\
\hline Formal & 425 & 43.6 \\
\hline \multicolumn{3}{|c|}{ Maternal occupation } \\
\hline Housewife & 311 & 32.0 \\
\hline Farmer & 207 & 21.1 \\
\hline Office & 155 & 15.9 \\
\hline Other & 298 & 30.7 \\
\hline \multicolumn{3}{|l|}{ Water source } \\
\hline Indoor pipe & 565 & 57.9 \\
\hline Outdoor pipe & 301 & 30.9 \\
\hline Wells & 83 & 8.5 \\
\hline River and rain & 23 & 2.4 \\
\hline
\end{tabular}

Family size

$\begin{array}{lrr}2-5 & 630 & 65.4 \\ 6-9 & 313 & 32.5 \\ 10-13 & 21 & 2.2\end{array}$

Type of toilet

\begin{tabular}{lcc}
\hline Flush toilet & 42 & 4.3 \\
\hline Ventilated pit & 49 & 5 \\
\hline Traditional pit & 802 & 82.3 \\
\hline Field & 77 & 7.9 \\
\hline H. pylori status & & \\
Positive & 343 & 36 \\
\hline Negative & 611 & 64 \\
\hline
\end{tabular}

type and site of waste disposal were all found to be potential confounders for $H$. pylori infection (online supplementary tables $\mathrm{S} 1$ ). When compared between males and females, there were no significant differences for most haematological parameters except for MCHC and RBC counts $(\mathrm{p}<0.05)$ (online supplementary table S2).

\section{Association between $\boldsymbol{H}$. pylori infection and platelet counts}

Linear regression models related platelet counts per $\mu \mathrm{L}$ of blood (continuous outcomes) to the individual estimates of $H$. pylori infection status (exposures). These showed a significant reduction in mean platelet counts among children infected with $H$. pylori compared with non-infected children (mean difference: $-21.95 \times 10^{9} / \mathrm{L} ; 95 \%$ CI -34.3 to $-9.58, \mathrm{p}=0.001$ ). When the analysis was adjusted for potential confounders, such as sex, age, family size and toilet type, the findings did not materially alter the magnitude of the effect estimate (table 2). In separate multivariate analysis adjusted for a priori confounders, $H$. pylori-infected individuals had a lower average MPV and RBC than uninfected individuals (adjusted mean difference: $-0.236 \mathrm{fL} ; 95 \% \mathrm{CI}-0.408$ to $-0.065, \mathrm{p}=0.007$ and adjusted mean difference: $-0.118 \times 10^{12} / \mathrm{L} ; 95 \% \mathrm{CI}-0.200$ to $-0.036, \mathrm{p}=0.005$, respectively) (table 2 ). Additionally, participants infected with $H$. pylori had an elevated WBC compared with uninfected individuals $(p=0.02)$ after adjusting for sociodemographic characteristics (table 2).

\section{Association between $\mathrm{H}$. pylori infection and platelet count category}

Table 3 presents the results of multinomial logistic regression analysis for association between $H$. pylori infection and platelet count category (ie, low, high and normal platelet counts). Children infected with $H$. pylori had 1.26fold higher odds of having low platelet counts (defined platelet counts $<150 \times 10^{9} / \mathrm{L}$ ) compared with those of non-infected, though we failed to reach statistical significance (adjusted OR: 1.26 ; 95\% CI 0.53 to 3.01, p >0.05) (table 3). Comparison with reference ranges used for classifying thrombocytopenia and thrombocytosis (platelet count $<150 \times 10^{9} / \mathrm{L}$ or $>450 \times 10^{9} / \mathrm{L}$, respectively) is also reported in online supplementary table S3. About $3.2 \%$ of $H$. pylori-infected children were found to be thrombocytopenic (platelet count $<150 \times 10^{9} / \mathrm{L}$ ).

\section{Association between $\boldsymbol{H}$. pylori infection and MPV category}

In a separate multinomial logistic model adjusted for potential confounders, children infected with $H$. pylori showed a significantly decreased odds of having high MPV (defined MPV $>10.5 \mathrm{fL}$ ) compared with those of non-infected (adjusted OR: 0.27 ; 95\% CI 0.17 to 0.44 , $\mathrm{p}<0.05)$. Further, H. pylori-infected children had higher odds of having low MPV (defined MPV $<7.0 \mathrm{fL}$ ), though not significant (adjusted OR: 1.60; 95\% CI 0.25 to 10.12, $\mathrm{p}>0.05$ ) (table 4). Comparison with normal ranges used for classifying high and low MPV level (MPV $<7 \mathrm{fL}$ or $>10.5 \mathrm{fL}$, respectively) is also reported in online supplementary table S4. A slightly higher proportion of low MPV level $(<7 \mathrm{fL})$ was found in $H$. pylori-infected children than non-infected ( $1 \%$ vs $0.4 \%$, respectively) (online supplementary table $\mathrm{S} 4$ ).

\section{DISCUSSION}

This study adds to the evidence on the influence of $H$. pylori infection on platelet parameters among apparently healthy school children in Ethiopia. We found that platelet counts and MPV were significantly lowered in 
Table 2 Multivariate generalised linear model of haematological parameters in association with Helicobacter pylori infection in school children, Ethiopia

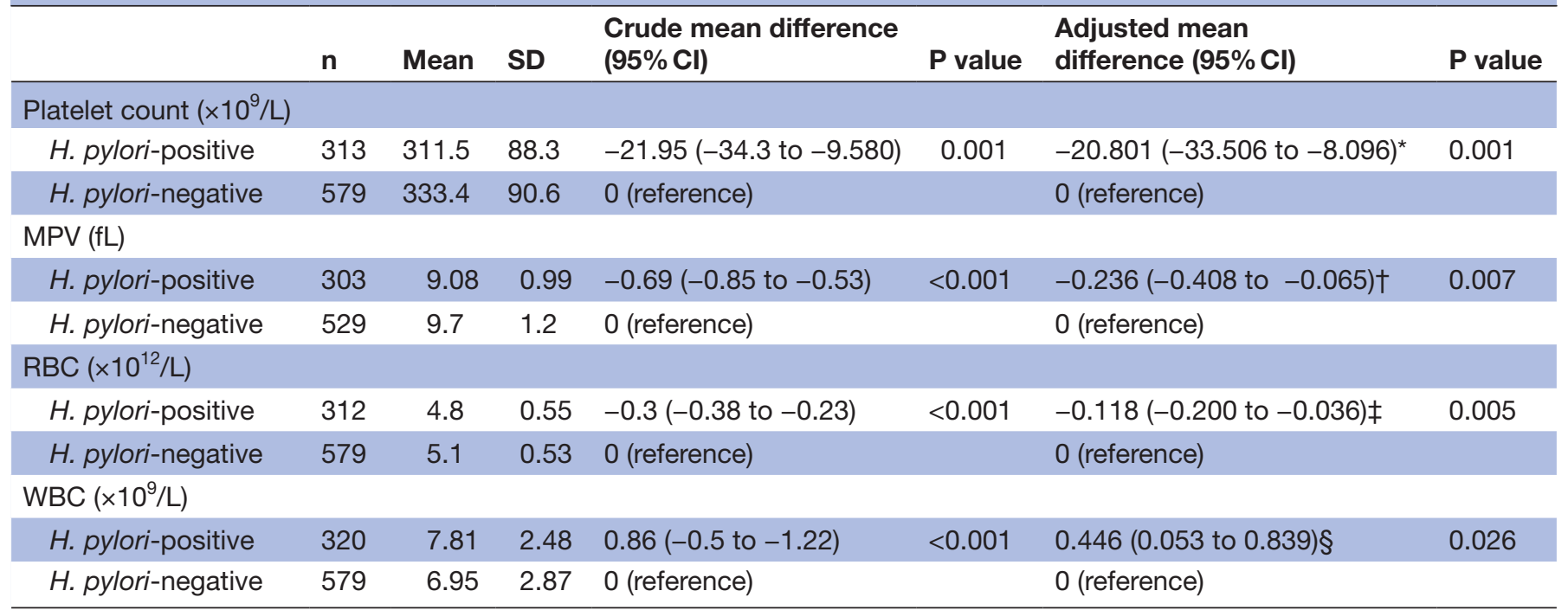

*Adjusted for toilet type, sex, age and family size.

†Adjusted for maternal education, maternal occupation, sex, age and residence.

$\ddagger$ Adjusted for maternal occupation, sex, age and residence.

$\S$ Adjusted for age, sex and residence.

MPV, mean platelet volume; RBC, red blood cell; WBC, white blood cell.

children infected with $H$. pylori compared with non-infected children. We also found that children infected with H. pylori were more likely to have platelet counts and MPV below the normal lower limit compared with those not infected.

Most studies investigating the link between $H$. pylori infection and platelet parameters to date have been retrospective clinical studies aimed to evaluate the effectiveness of $H$. pylori eradication treatment on ITP patients, ${ }^{10-13}$ and most reported an increased platelet count after successful eradication of $H$. pylori infection among those patients diagnosed with ITP. However, studies in apparently healthy populations, particularly those from low-income countries, are remarkably scarce. One study by Umit and Umit in Turkey analysed platelet count as it related to $H$. pylori infection before the onset of ITP, ${ }^{16}$ and they reported a significant decrease in mean platelet count among $H$. pylori-positive individuals than those who were H. pylori-negative $(\mathrm{p}<0.001)$, which is consistent with the finding of the current study. Our findings are also consistent with those of another cross-sectional study reported by Raza and Bilaal ${ }^{22}$ from Pakistan and Ali and Gaufri ${ }^{23}$ from Sudan, who found lower platelet counts in $H$. pylori-infected individuals compared with non-infected. In contrast with these findings, no significant difference in platelet counts between $H$. pylori-infected $(\mathrm{n}=108)$ and $H$. pylori-non-infected patients $(\mathrm{n}=600)$ was reported in a cross-sectional study from the Netherlands. ${ }^{24}$ These inconsistent findings could be due to variations in age, outcome ascertainment and differences in the method used for the assessment of $H$. pylori status. More importantly, among these studies, there were differences in the distribution of factors that affect platelet counts and differences in study design.

Table 3 Association of platelet counts with Helicobacter pylori infection according to traditional cut-offs for thrombocytosis and thrombocytopenia in school children, Ethiopia. Multivariate multinomial regression analysis

\section{Platelet count classification*}

\begin{tabular}{|c|c|c|c|c|}
\hline \multirow[b]{2}{*}{ H. pylori status } & \multicolumn{2}{|c|}{ Low platelet count $<150 \times 10^{9}$ platelets $/ \mathrm{L}$} & \multicolumn{2}{|c|}{ High platelet count $>450 \times 10^{9}$ platelets $/ L$} \\
\hline & Crude OR (95\% Cl) & Adjusted OR† $(95 \% \mathrm{Cl})$ & Crude OR $(95 \% \mathrm{Cl})$ & Adjusted OR† $(95 \% \mathrm{Cl})$ \\
\hline H. pylori-positive & 1.53 (0.65 to 3.59$)$ & $1.26(0.53$ to 3.01$) \ddagger$ & 0.77 (0.46 to 1.30$)$ & $0.70(0.41$ to 1.21$) \ddagger$ \\
\hline
\end{tabular}

*Platelet counts were categorised to form polytomous outcome variable as either low, high or normal using the cut-offs as described by the British Journal of Haematology for multinomial regression analysis. Normal platelet counts (150-450 platelets $\left.10^{9} / \mathrm{L}\right)$ was used as a reference category in multinomial regression.

†Adjusted for sex, age, haemoglobin and WBC.

$\ddagger P>0.05$.

WBC, white blood cell. 
Table 4 Association of mean platelet volume (MPV) with Helicobacter pylori infection according to the reference interval in school children, Ethiopia. Multivariate multinomial regression analysis

\begin{tabular}{|c|c|c|c|c|}
\hline \multicolumn{5}{|c|}{ MPV classification* } \\
\hline \multirow[t]{2}{*}{ H. pylori status } & \multicolumn{2}{|l|}{ Low MPV (<7fL) } & \multicolumn{2}{|l|}{ High MPV (>10.5fL) } \\
\hline & Crude OR (95\% Cl) & Adjusted OR† (95\% Cl) & Crude OR (95\% Cl) & Adjusted OR† $(95 \% \mathrm{Cl})$ \\
\hline H. pylori-negative & 1 & 1 & 1 & 1 \\
\hline
\end{tabular}

*MPV was categorised to form polytomous outcome variable as either low, high or normal using the cut-offs described by the British Journal of Haematology for multinomial regression analysis. Normal MPV (7-10.5 fL) was used as a reference category in multinomial regression. †Adjusted for sex, age, place of residence, haemoglobin and WBC. $\ddagger P>0.05$. $\S \mathrm{P}<0.05$.

WBC, white blood cell.

In this study, a significantly lower MPV along with low platelet counts in children infected with $H$. pylori compared with non-infected can be contrasted with previous reports. Two cross-sectional studies in Turkey ${ }^{16}$ and Sudan ${ }^{23}$ reported a significantly higher MPV level in $H$. pylori-infected individuals than non-infected. These authors speculated an ongoing and compensated platelet destruction-production process as possible justification for the increase in MPV. Indeed, a high MPV value is related with an increase in the entry of young platelets into circulation from the bone marrow either due to the high destruction of platelets or severe systemic inflammatory conditions, such as rheumatoid arthritis and inflammatory bowel disease. ${ }^{25}$ However, our study population is distinctly different, as all are apparently healthy children, and severe systemic inflammatory conditions would not be expected to occur in the current study. In contrast to this hypothesis, however, a decreased MPV level has been found in studies related with localised inflammatory disease, such as gastrointestinal diseases. ${ }^{20}{ }^{26} \mathrm{~A}$ study by Matowicka-Karna and Panasiuk ${ }^{20}$ reported significantly lower MPV levels in patients infected with Entamoeba histolytica than in controls. Similarly, Mete et $a l^{26}$ showed a lower MPV in children infected with rotavirus gastroenteritis than in healthy controls. Although the pathogenesis of decreased MPV levels in intestinal inflammation has not been fully explained, it seems reasonable to explain this with the sequestration of large active platelets in the vascular segments of the inflamed bowel, which may cause a relative decrease in the circulation. In our study, the finding that children infected with $H$. pylori have decreased MPV may be related to a localised gastrointestinal inflammation. It has been shown that $H$. pylori-related injury in the gastric mucosal cells led to local inflammation in the gastric mucosa by neutrophils and other inflammatory cells. ${ }^{27}$

Our findings should be interpreted in light of the following limitations. First, we did not measure different strains of $H$. pylori, and in previous studies, a more pronounced reduction in mean platelet counts was observed among individuals infected with the more virulent CagA+ H. pylori strains. ${ }^{12}{ }^{28}$ Although we have no data on CagA serology, a previous study in dyspeptic Ethiopian patients detected CagA genes in $79 \%$ of the study subjects, ${ }^{29}$ suggesting that this may be the dominant strain in the population. Second, we could not thoroughly investigate the previous use of antiplatelet agents, which is known to affect platelets indices. ${ }^{25}$ However, our study population is from a low-income area with limited access to standard treatment, making this an unlikely explanation for the observed association between low platelets indices and $H$. pylori infection. Additionally, we used EDTA anticoagulant agent that has been associated with time-dependent ultrastructural morphological changes of platelets; ${ }^{30}$ thus, affecting MPV values. However, our samples were tested within 1-2 hours of blood collection making it unlikely that this affected MPV measurement. A further limitation of the current study is its cross-sectional design, which makes it difficult to attribute causality (ie, $H$. Pylori infection lead to low platelet indices directly) since we did not have information on ITP or haematological parameters prior to infection. Research employing a longitudinal design is required in the future. Finally, $H$. pylori infection might also be a proxy indicator of other infections or socioeconomic conditions. ${ }^{31}$ To explore such a possibility, the findings were adjusted for markers of socioeconomic status and intestinal parasite infections, none of which significantly modified the effect estimates. The possibility of reverse causation is difficult to fully eliminate, but acquisition of $H$. pylori infection in developing countries usually occurs during infancy and very early life, ${ }^{32} 33$ which limits the possibility that low MPV level preceded $H$. pylori infection.

Studies in clinical settings have implicated that infections other than $H$. pylori, such as malaria ${ }^{34}$ and viral infections, ${ }^{35}$ may lead to low platelet levels. Although this remains a possibility, our study was conducted on apparently healthy school children from April to July before the peak season for malaria transmission in Ethiopia. Moreover, Sululta town, where the majority of the schools were located, has an altitude of $2450 \mathrm{~m}$ above sea level, so with temporal and spatial considerations, malaria transmission is expected to be very low and unlikely to be an alternative explanation for our findings. Furthermore, we had 
data on intestinal parasite status and $\mathrm{C}$ reactive protein (as proxy indicator for overall infections and inflammations), and none of these significantly modified the effect estimates (data not shown).

Despite these limitations, the main strength of this study is the large, population-based study sample, unlike most of the previous studies that have used patients in a clinical setting, thereby minimising our selection bias. We have also used a highly sensitive and specific $H$. pylori stool antigen test. ${ }^{36}$ Additionally, measurement of the key outcomes (platelet indices) was done using a standard automated haematology analyser, which was calibrated on a regular basis according to the manufacturer's guidelines.

Several hypotheses have been proposed regarding the mechanism by which $H$. pylori induces the development of thrombocytopenia. One of them is molecular mimicry, according to which $H$. pylori could induce antibody production in response to antigens that cross-react against various platelet glycoprotein antigens. ${ }^{12}$ Others have proposed the possibility of $H$. pylori-induced platelet aggregation resulting from the interaction of $H$. pylori-bound von Willebrand factor and anti-H. pylori (IgG) antibodies with platelet surface antigen (GPIb) ${ }^{37}$ Furthermore, enhanced platelet activation from the binding of vacuolating cytotoxin (VacA) virulence factor to multimerin one on platelets, ${ }^{38}$ and the down-regulation of Fc $\gamma$ RIIB receptors on monocytes, resulting in increased phagocytic activity by $H$. pylori infection have also been proposed as plausible mechanisms.

\section{CONCLUSION}

In conclusion, this cross-sectional study from a developing country provides further support for an association between $H$. pylori infections and reduced platelet counts and MPV in young Ethiopian children, after controlling for potential confounders. Further research is needed, particularly longitudinal studies, to establish causality.

Acknowledgements We gratefully thank the mothers and children at each school who generously provided information, and the project data collectors and the laboratory technicians for their commitment during the fieldwork.

Contributors BT conceived and designed the study, collected data in the field and wrote this manuscript. KB participated in data analysis and interpretation and prepared the preliminary results. SW, MT, MW, DA and AM participated in data collection, performed analysis, interpretation of data and the critical review of the manuscript. AT, KD and MW participated in data collection and interpretation and critically reviewed the manuscript. All authors read and approved the final manuscript.

Funding Colgate University research council funded the study.

Disclaimer The views expressed are those of the author(s) and not necessarily those of the Colgate University or the Addis Ababa University Collage of Health Sciences.

\section{Competing interests None declared.}

Patient consent for publication Parental/guardian consent obtained.

Ethics approval The study was approved by the Departmental Research and Ethics Review Committee (DRERC) at Department of Medical Laboratory Sciences, Addis Ababa University College of Health Sciences, Ethiopia.
Provenance and peer review Not commissioned; externally peer reviewed.

Data sharing statement The data sets used and/or analysed in the current study will be available from the corresponding author on reasonable request.

Open access This is an open access article distributed in accordance with the Creative Commons Attribution Non Commercial (CC BY-NC 4.0) license, which permits others to distribute, remix, adapt, build upon this work non-commercially, and license their derivative works on different terms, provided the original work is properly cited, appropriate credit is given, any changes made indicated, and the use is non-commercial. See: http://creativecommons.org/licenses/by-nc/4.0/.

\section{REFERENCES}

1. Potamitis GS, Axon AT. Helicobacter pylori and nonmalignant diseases. Helicobacter 2015;20 Suppl 1(Suppl 1):26-9.

2. Malfertheiner P, Link A, Selgrad M. Helicobacter pylori: perspectives and time trends. Nat Rev Gastroenterol Hepatol 2014;11:628-38.

3. Uemura N, Okamoto S, Yamamoto S, et al. Helicobacter pylori infection and the development of gastric cancer. N Engl J Med 2001;345:784-9.

4. Kuipers EJ, Thijs JC, Festen HP. The prevalence of Helicobacter pylori in peptic ulcer disease. Aliment Pharmacol Ther 1995;2:59-69.

5. Nomura A, Stemmermann GN, Chyou PH, et al. Helicobacter pylori infection and the risk for duodenal and gastric ulceration. Ann Intern Med 1994;120:977-81.

6. Queiroz DM, Rocha AM, Crabtree JE. Unintended consequences of Helicobacter pylori infection in children in developing countries: iron deficiency, diarrhea, and growth retardation. Gut Microbes 2013;4:494-504.

7. Pacifico L, Anania C, Osborn JF, et al. Consequences of Helicobacter pylori infection in children. World J Gastroenterol 2010;16:5181-94.

8. Taye B, Enquselassie F, Tsegaye A, et al. Effect of early and current Helicobacter pylori infection on the risk of anaemia in 6.5-year-old Ethiopian children. BMC Infect Dis 2015;15:270.

9. Taye B, Enquselassie F, Tsegaye A, et al. Effect of Helicobacter pylori infection on growth trajectories in young Ethiopian children: a longitudinal study. Int J Infect Dis 2016;50:57-66.

10. Gasbarrini A, Franceschi F, Tartaglione R, et al. Regression of autoimmune thrombocytopenia after eradication of Helicobacter pylori. Lancet 1998;352:878.

11. Emilia G, Longo G, Luppi M, et al. Helicobacter pylori eradication can induce platelet recovery in idiopathic thrombocytopenic purpura. Blood 2001;97:812-4

12. Takahashi T, Yujiri T, Shinohara K, et al. Molecular mimicry by Helicobacter pylori CagA protein may be involved in the pathogenesis of $\mathrm{H}$. pylori-associated chronic idiopathic thrombocytopenic purpura. Br J Haematol 2004;124:91-6.

13. Kodama M, Kitadai $\mathrm{Y}$, Ito $\mathrm{M}$, et al. Immune response to CagA protein is associated with improved platelet count after Helicobacter pylori eradication in patients with idiopathic thrombocytopenic purpura. Helicobacter 2007;12:36-42.

14. Franchini M, Cruciani M, Mengoli C, et al. Effect of Helicobacter pylori eradication on platelet count in idiopathic thrombocytopenic purpura: a systematic review and meta-analysis. J Antimicrob Chemother 2007;60:237-46.

15. Chmiela M, Gonciarz W. Molecular mimicry in Helicobacter pylori infections. World J Gastroenterol 2017;23:3964-77.

16. Umit H, Umit EG. Helicobacter pylori and mean platelet volume: a relation way before immune thrombocytopenia? Eur Rev Med Pharmacol Sci 2015;19:2818-23.

17. Gasbarrini A, Franceschi F. Does H. Pylori infection play a role in idiopathic thrombocytopenic purpura and in other autoimmune diseases?. Am J Gastroenterol 2005;100:1271-3.

18. Amberbir A, Medhin G, Erku W, et al. Effects of Helicobacter pylori, geohelminth infection and selected commensal bacteria on the risk of allergic disease and sensitization in 3-year-old Ethiopian children. Clin Exp Allergy 2011;41:1422-30.

19. Segal I, Ally R, Mitchell H. Helicobacter pylori-an African perspective. QJM 2001:94:561-5.

20. Matowicka-Karna J, Panasiuk A. Does anti-parasitic treatment normalize platelets morphology in patients infested with Entamoeba histolytica? Rocz Akad Med Bialymst 1996;41:258-67.

21. Giles $\mathrm{C}$. The platelet count and mean platelet volume. Br J Haematol 1981;48:31-7.

22. Raza $\mathrm{AB}$, Bilaal $\mathrm{MH}$. Comparison of platelet counts between $\mathrm{H}$. pylori infected and non-infected individuals. P J M H S 2016;10:405-8.

23. Ali SA, Gaufri NEAM. Platelet characterization in helicobacter pylori patients. OAlib 2017;04:1-6. 
24. Samson AD, Schipperus MR, Langers AM, et al. Helicobacter pylori infection is not correlated with subclinical thrombocytopenia: a cross-sectional study. Platelets 2014;25:221-3.

25. Gasparyan AY, Ayvazyan L, Mikhailidis DP, et al. Mean platelet volume: a link between thrombosis and inflammation? Curr Pharm Des 2011;17:47-58.

26. Mete E, Akelma AZ, Cizmeci MN, et al. Decreased mean platelet volume in children with acute rotavirus gastroenteritis. Platelets 2014;25:51-4.

27. Ernst PB, Crowe SE, Reyes VE. How does Helicobacter pylori cause mucosal damage? The inflammatory response. Gastroenterology 1997;113:S35-S42.

28. Sibanda N, Blacklock $\mathrm{H}$, Zeng I, et al. Helicobacter pylori infection and the platelet count. N Z J Med Lab Sci 2016;70:96-100.

29. Asrat $D$, Nilsson I, Mengistu Y, et al. Prevalence of Helicobacter pylori vacA and cagA genotypes in Ethiopian dyspeptic patients. $J$ Clin Microbiol 2004;42:2682-4.

30. Bath PM. The routine measurement of platelet size using sodium citrate alone as the anticoagulant. Thromb Haemost 1993;70:687-90.

31. Ford AC, Forman D, Bailey AG, et al. Effect of sibling number in the household and birth order on prevalence of Helicobacter pylori: a cross-sectional study. Int J Epidemiol 2007;36:1327-33.
32. Sullivan PB, Thomas JE, Wight DG, et al. Helicobacter pylori in Gambian children with chronic diarrhoea and malnutrition. Arch Dis Child 1990;65:189-91.

33. Kehrt R, Becker M, Brösicke H, et al. Prevalence of Helicobacter pylori infection in Nicaraguan children with persistent diarrhea, diagnosed by the 13C-urea breath test. J Pediatr Gastroenterol Nutr 1997;25:84-8.

34. Shaikh MA, Ahmed S, Diju IU, et al. Platelet count in malaria patients. J Ayub Med Coll Abbottabad 2011;23:143-5.

35. Kim JK, Jeon JS, Kim JW, et al. Correlation between abnormal platelet count and respiratory viral infection in patients from cheonan, Korea. J Clin Lab Anal 2016;30:185-9.

36. Vaira D, Malfertheiner P, Mégraud F, et al. Noninvasive antigen-based assay for assessing Helicobacter pylori eradication: a European multicenter study. The European Helicobacter pylori HpSA Study Group. Am J Gastroenterol 2000;95:925-9.

37. Byrne MF, Kerrigan SW, Corcoran PA, et al. Helicobacter pylori binds von Willebrand factor and interacts with GPIb to induce platelet aggregation. Gastroenterology 2003;124:1846-54.

38. Satoh K, Hirayama T, Takano K, et al. VacA, the vacuolating cytotoxin of Helicobacter pylori, binds to multimerin 1 on human platelets. Thromb J 2013;11:23. 